\title{
تطوير مادة تعليم المفردات لبرنامج “صباح اللغة” على أساس النظرية السلوكية لطلبة معهد الجامعة
}

\author{
Ahmad Mujib', Ahmad Bashori \\ 1IAIN Ponorogo, ${ }^{2}$ IAIN Ponorogo \\ 1Mujiba101@gmail.com, ${ }^{2}$ bashori684@gmail.com
}

\section{Abstrct}

The purpose of this study is to describe the development of Mufradat learning material in the 'Shabahul Lughah' Program in IAIN Ponorogo based on the theory of behaviorism. The research method used is R\&D according to Gall and Borg's theory. The results of the study includes: 1) the steps of developing the Mufradat learning material on the 'shabahul Lughah' program, are: problem limitation and needs analysis, gathering information as a basis for developing the material, designing the mufradat learning framework based on the theory of behaviorism, designing the material writing framework, selecting themes and sequence, design content and exercises, and products in the form of books, 2) mufradat learning material suitable for use in IAIN Ponorogo 'shabahul Lughah' Program, 3) mufradat learning material based on the theory of behaviorism effectively to help students and teachers in Ma'had Ulil Abshar into realizing the goal of mufradat learning.

Keywords: development, mufradat learning material, behaviorism theory.

\section{Abstrak}

Tujuan studi ini adalah untuk mendeskripsikan pengembangan materi pembelajaran Mufradat pada Program 'shabahul Lughah' berdasarkan teori behaviorisme. Metode penelitian yang dipakai adalah R\&D sesuai teori Gall dan Borg. Adapun hasil penelitian meliputi: 1) langkah pengembangan materi pembelajaran Mufradat pada Program 'shabahul Lughah', yaitu: pembatasan masalah dan analisis kebutuhan, pengumpulan infromasi sebagai dasar pengembangan materi, mendesain kerangka pembelajaran mufradat berdasarkan teori behaviorisme, merancang kerangka penulisan materi, pemilihan tema dan urutannya, merancang konten dan latihan, dan produk berupa buku, 2) materi pembelajaran mufradat cocok untuk digunakan dalam Program 'shabahul Lughah' IAIN Ponorogo, 3) materi pembelajaran mufradat berdasarkan teori behaviorisme efektif untuk membantu santri dan para pengajar dalam mewujudkan pembelajaran mufradat.

Kata kunci: pengembangan, materi pembelajaran mufradat, teori behaviorisme. 
إن تعليم المفردات مطلب أساسي من مطالب تعليم اللغة العربية. وحقيقة اللغة مجموعة من المفردات حتى لا يمكن الناس فهم اللغة قبل معرفة معاني المفردات منها. إن

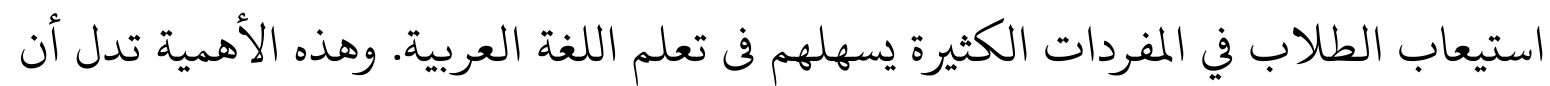
تعلّم المفردات أمر ضروري لأنها عنصر من عناصر اللغة في تعليم اللغة العربية.

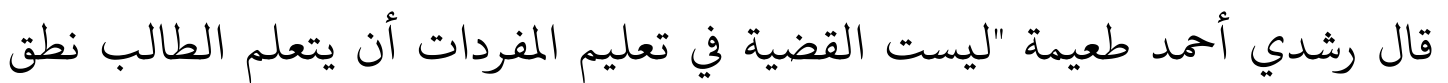

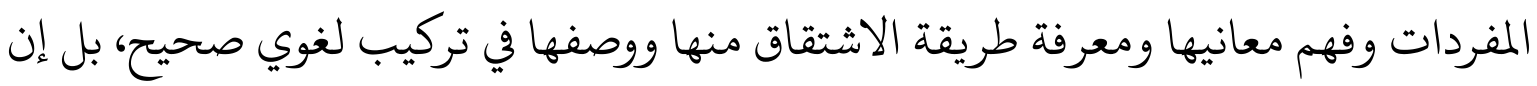

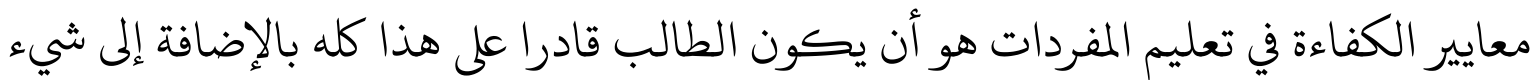
لا يقل عن هذا كله أهمية، ألا وهو قدرته على أن يستخدم الكلمة المناسبة في المكان المناسب". فالمفهوم من هذا القول أن تعليم المفردات لا يقتصر في حفظ المفردات ومعانيها فحسب، بل هل فيل أن يكون الهدف الأقصى لتعليم المفردات هو استخدام المفردات في الكلام. وذهب سافير أن تعلم اللغة لا يقتصر بتعلم مفرداتها لأن متعلمي اللغة غير الناطقين

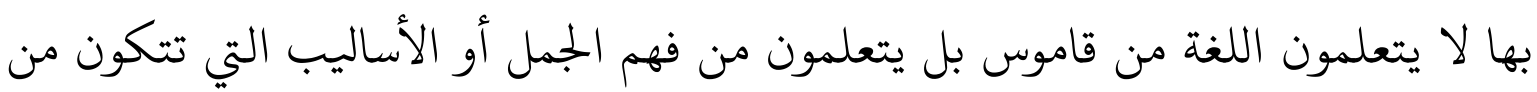

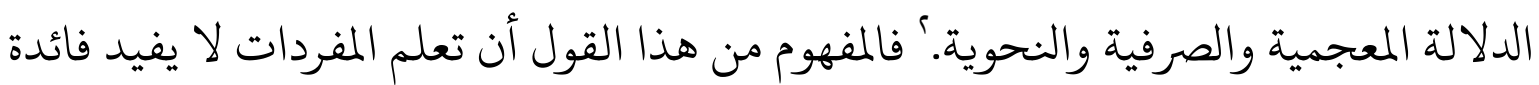
إذا تعلمها الطالب وحدها دون الارتباط بالجملة والأساليب، فتعلم المفردات المفيد إذا والها تعلمها الطالب مع ارتباطها بالجملة والأساليب. إن معهد أولي الأبصار بالجامعة الإسلامية الحهكومية فونوروكو جاوى الشرقية أحدالية من معاهد الجامعات الإسلامية الحكومية في إندونيسيا الذي قام ببرنامج تعليم اللغة العربية.

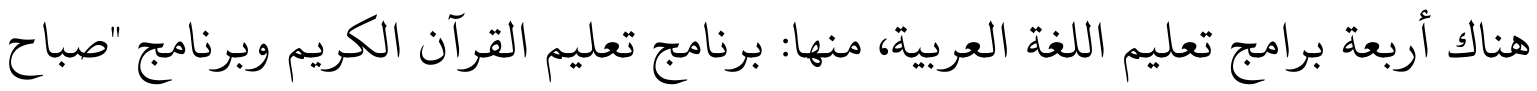
اللغة" لتعليم المفردات وبرنامج تعليم اللغة العربية وبرنامج تعليم كتب التراث الإسلامي. وركز الباحث بحثه في برنامج "صباح اللغة" لتعليم المفردات.

'رشدي أحمد طعيمة، تعليم اللغة العربية لغير الناطقين بها مناهجه و أساليبه (منثورات المنظمة الإسلامية

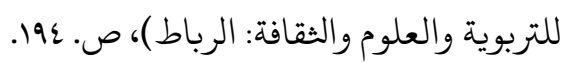

${ }^{2}$ Ahmad Fuad Effendi, Metodologi Pembelajaran Bahasa, Hal. 96. 
قد قام الباحث بالدراسة المبدئية في برنامج "صباح اللغة" لتعليم المفردات بمعهد

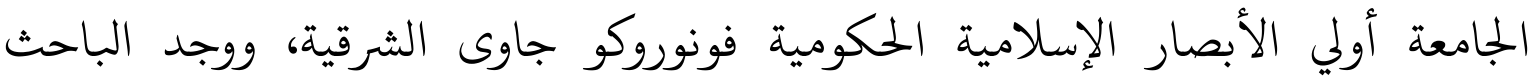
المشكلات في ذلك البرنامج. وتلك المشكلات كما يلي: ا - وفقا لنتيجة الملاحظة في برنامج "صباح اللغة" لتعليم المفردات، وجد الباحث أن تنفيذ عملية تعليم المفردات في بعض الفصول يدل على أن معايير كفاءة تعليم المفردات هناك

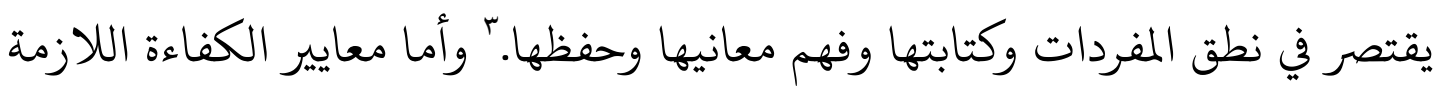

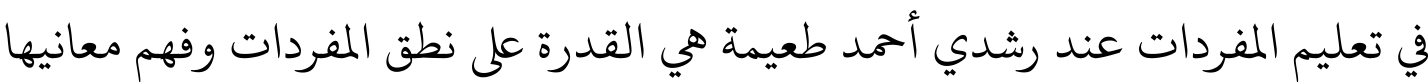
ومعرفة طريقة الاشتقاق منها ووصفها في تركيب لغوي صحيح واستخدامها في المكان المناسب. وذهب سيف المصطفى أن مؤشرات الاستيعاب في تعليم المفردات هي القدرة

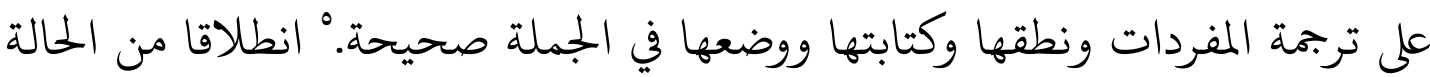

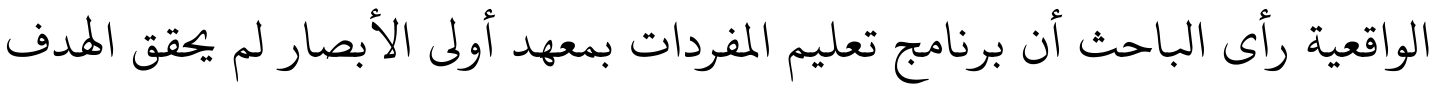

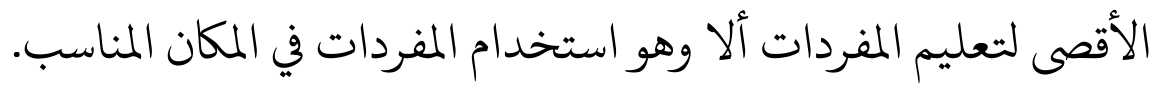

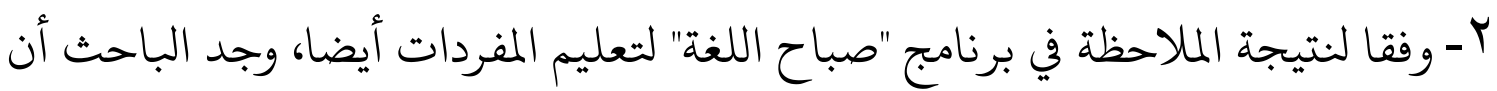

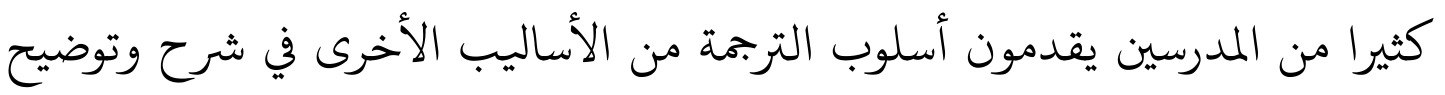

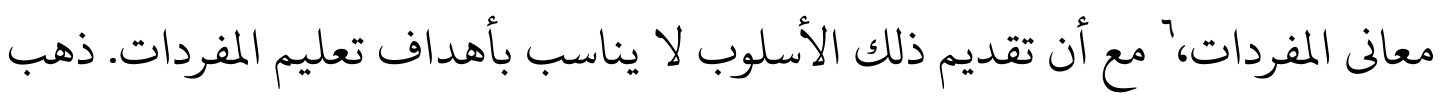
حمادة إبراهيم في كتابه "الاتجهات المعاصرة في تدريس اللغة العربية واللغة الحية

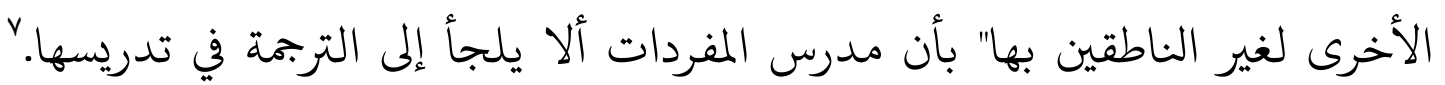

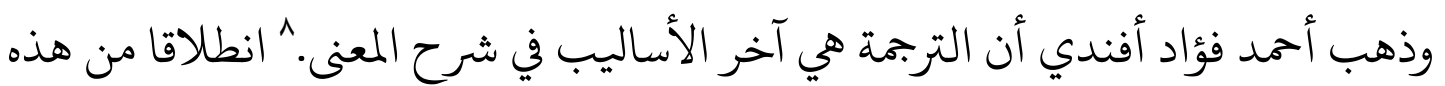

"نتيجة الملاحظة في برنامج "صباح اللغة" لتعليم المفردات بمعهد أولي الأبصار بالجامعة الإسلامية الحكومية

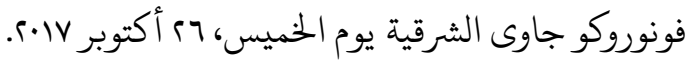

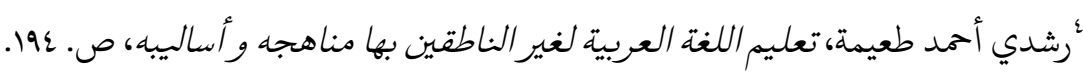

${ }^{5}$ Syaiful Mustofa, Strategi Pembelajaran Bahasa Arab Inovatif, (Malang : UIN Malang Press, 2011), Hal. 60.

"نتيجة الملاحظة في برنامج "صباح اللغة" لتعليم المفردات بمعهد أولي الأبصار بالجامعة الإسلامية الحكومية

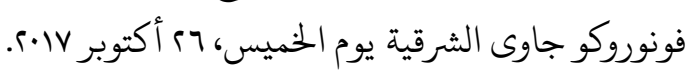
"حمادة إبراهيم، الاتجهات المعاصرة في تدريس اللغة العتربية العربية واللغة الحية الأخرى لغير الناطقين بها (دار الفكر

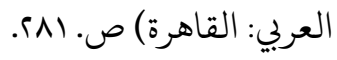

${ }^{8}$ Ahmad Fuad Effendi, Metodologi Pembelajaran Bahasa Arab, Hal. 99. 
الحالة الواقعية ذهب الباحث أن أسلوب بعض المدرسين في تعليم المفردات بمعهد أولى الأبصار لم يساعد في تحقيق أهداف تعليم المفردات لأن المدرسين يلجؤون الترجمة في تعليمها.

"- وفقا لنتيجة تحليل المادة المستخدمة في برنامج "صباح اللغة" لتعليم المفردات بمعهد أولى الأبصار، وجد الباحث أن المادة المستخدمة لا تتضمن إلا المحتوى أي أنها خلمادئ خالية

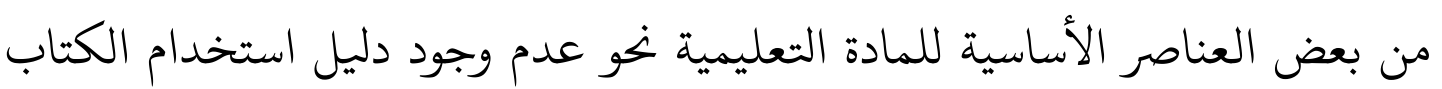

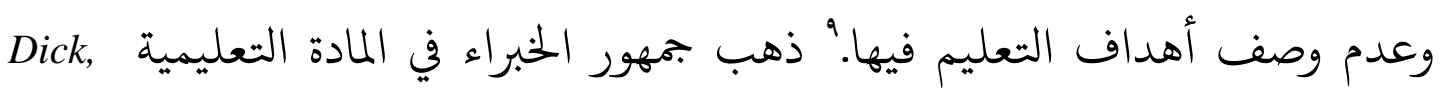
Carey, Degeng, Tarigan

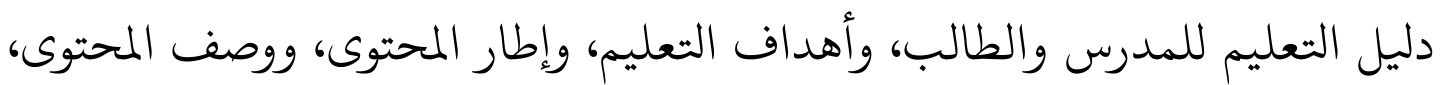

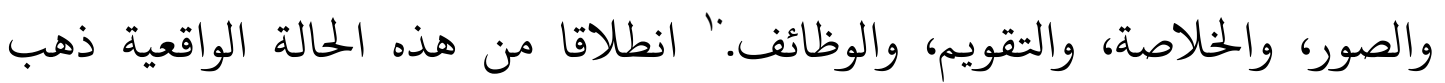

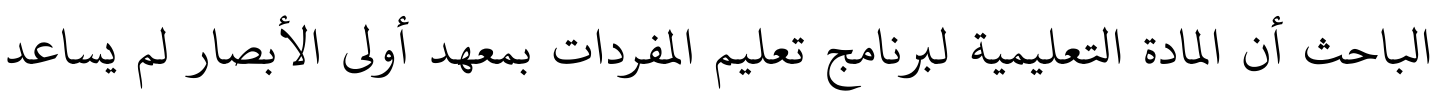

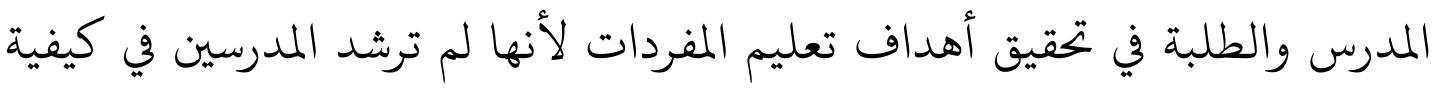

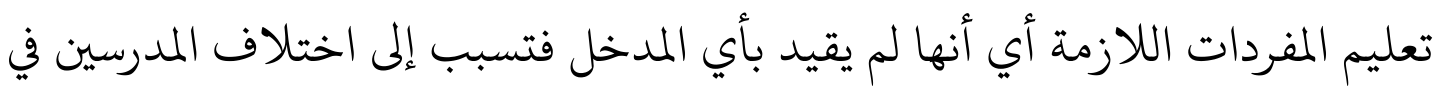
اختيار المدخل والطريقة في تعليم المفردات وتسبب إلى اختلاف مدى كفي كفاءة الطلبة في

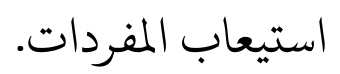

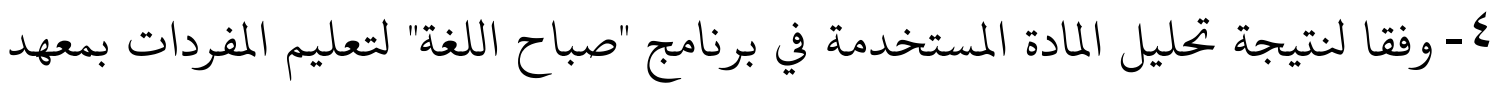

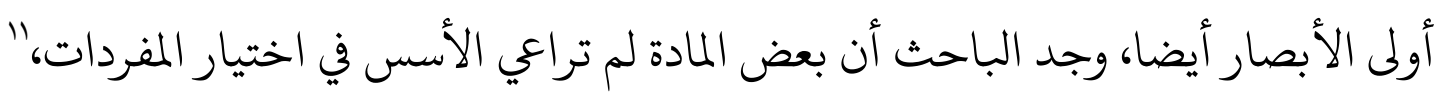

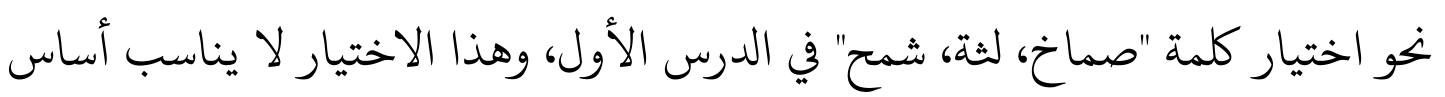

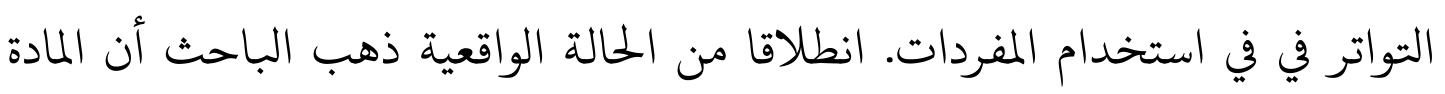

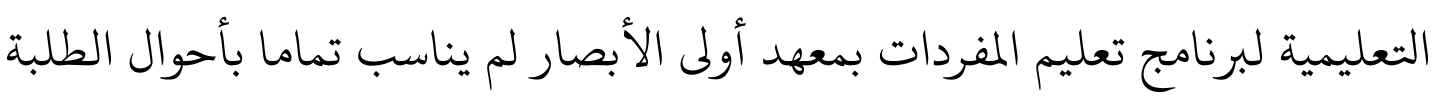

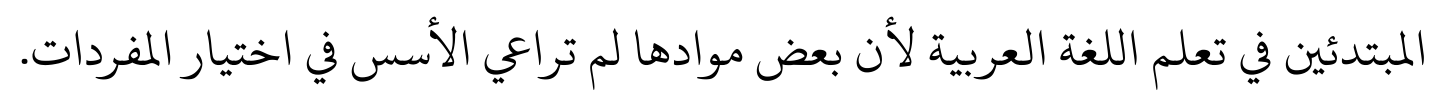

"كتاب "صباح اللغة" لتعليم المفردات لطلبة معهد أولى الأبصار بالجامعة الإسلامية الحكومية فونوروكو.

${ }^{10}$ Abdul Hamid dkk., Pembelajaran Bahasa Arab; Pendekatan, Metode, Strategi, Materi dan Media (Malang: UIN Malang Press, 2008), Hal. 71.

"كتاب "صباح اللغة" لتعليم المفردات لطلبة معهد أولى الأبصار بالجامعة الإسلامية الحكومية فونوروكو. 
واستنادا من نتيجة الدراسة المبدئية في ميدان البحث، قام الباحث بتطوير كتاب تعليم

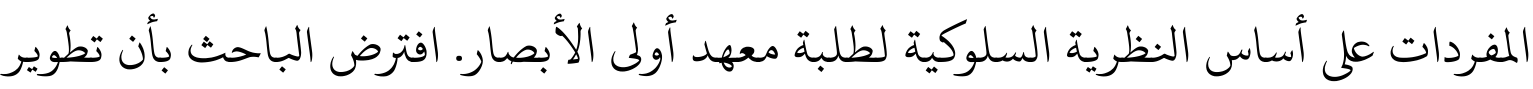

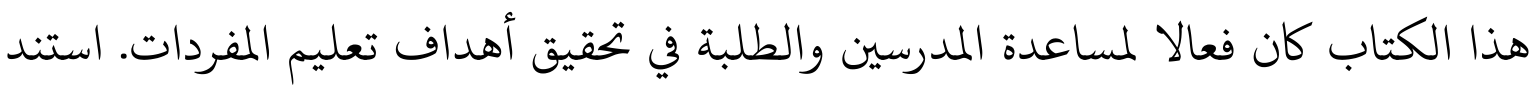
هذا الافتراض على تناسب الأهداف بين أهداف تعليم المفردات ومبادئ النظرية السلوكية في

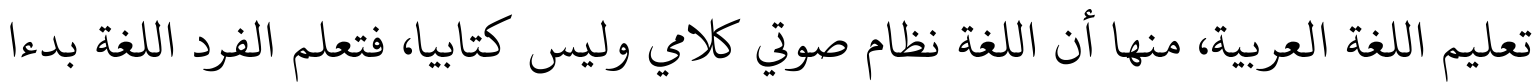

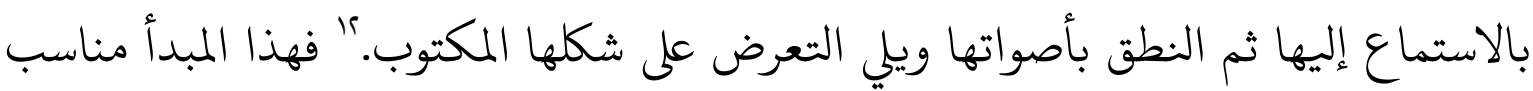

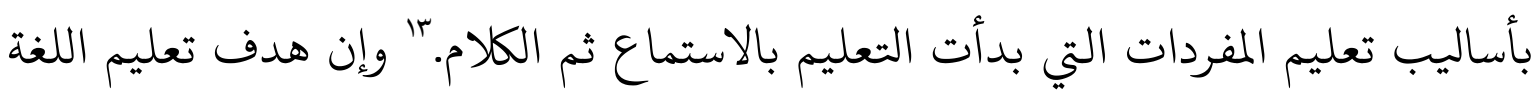

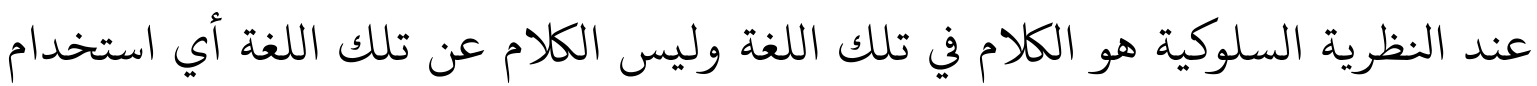

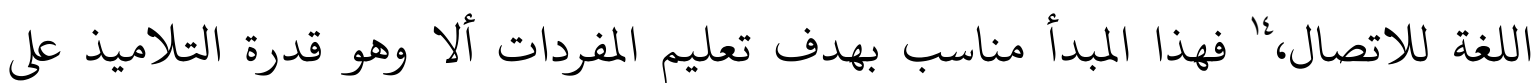
استخدام المفردات في المكان المناسب. ${ }^{\circ}$ وذهبت هذه النظرية أن البيئة التعليمية وسيلة

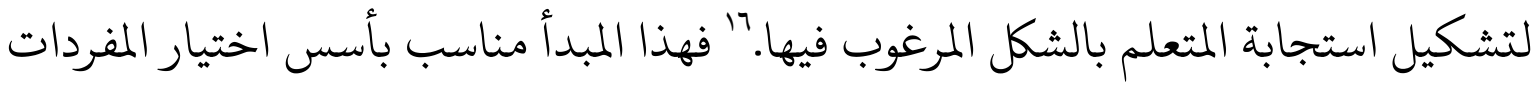

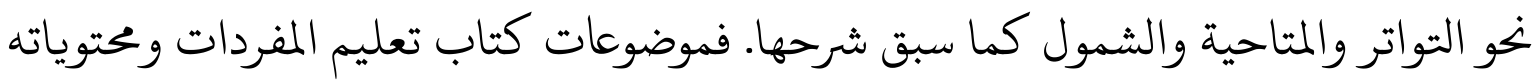

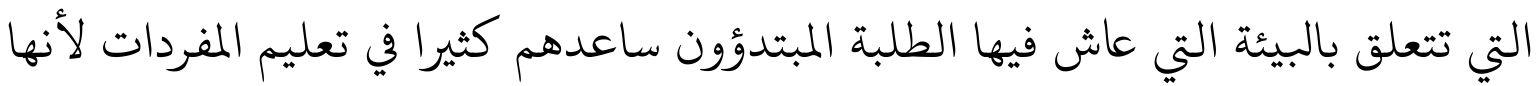

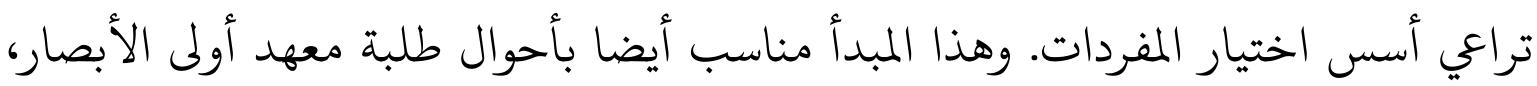

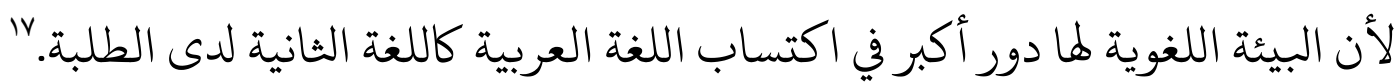
انطلاقا من أهيمة دور المادة التعليمية في مساعدة تحقيق أهداف التعليم وأهمة القيام بتحليل المشكلات والاحتياجات السابقة فقام الباحث بتطوير مادة تعليم المفردات لبرنامج “صباح اللغة” على أساس النظرية السلوكية لطلبة معهد الجامعة.

مفهوم المادة التعليمية

${ }^{12}$ Aziz Fakhrurrozi dan Erta Mahyudin, Pembelajaran Bahasa Arab, Hal. 46.

${ }^{13} \mathrm{Ahmad}$ Fuad Effendi, Metodologi Pembelajaran Bahasa Arab, Hal. 99.

${ }^{14}$ Aziz Fakhrurrozi dan Erta Mahyudin, Pembelajaran Bahasa Arab, Hal. 11.

$$
\text { "رشدي أحمد طعيمة، تعليم اللغة العربية لغير الناطقين بها مناهجه وأساليبه، ص. عأ. } 19 .
$$

${ }^{16}$ Aziz Fakhrurrozi dan Erta Mahyudin, Pembelajaran Bahasa Arab, Hal. 11.

"vنتيجة الملاحظة في برنامج "صباح اللغة" لتعليم المفردات بمعهد أولي الأبصار بالجامعة الإسلامية الحكومية

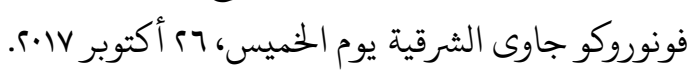


هناك آراء العلماء في بيان مفهوم المادة التعليمية، منها:

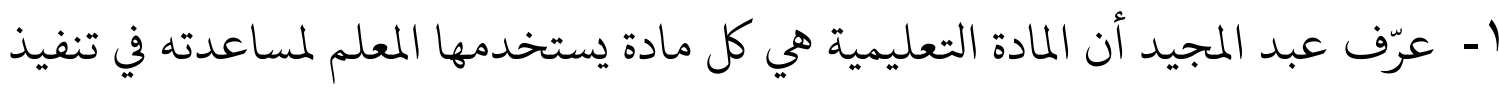

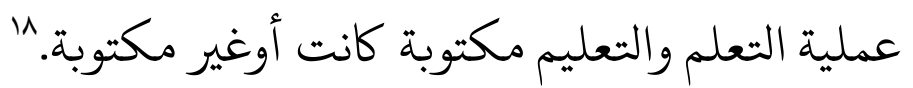

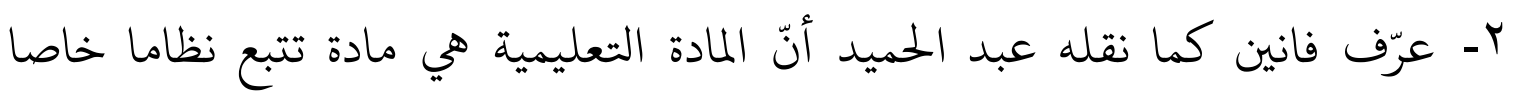
يستعملها المعلم والتلميذ في التعليم.

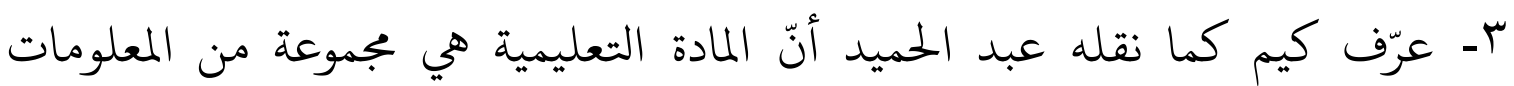
والمهارات والمواقف. ع- عرّف عبد الحميد وآخرون أنّ المادة التعليمية هي المادة التى تتكون من علم ومهارة وموقف تتبع نظاما خاصا ويستعملها المعلم والتلميذ في عملية التعليم. 19 هـ عرّف رشدي أحمد طعيمة أن المادة التعليمية هي مجموعة من الخبرات التربوية والحقائق

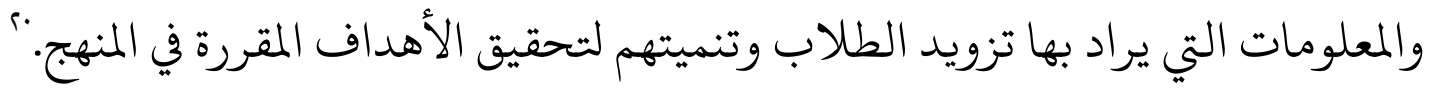

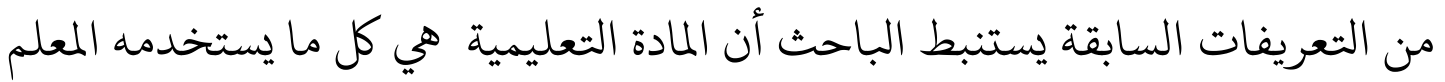
والطلاب ويساعدهم في تنفيذ عملية التعليم للحصول على الأهداف التعليمية.

\section{مفهوم تعليم المفردات}

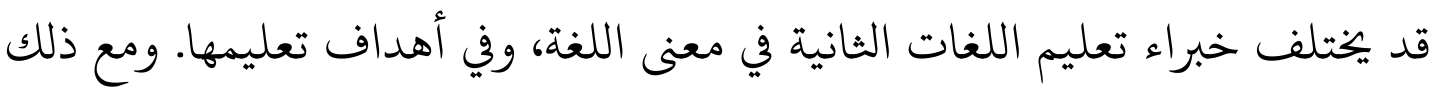
فإنهم يتفقون على أن تعلم المفردات مطلب أساسي من مطالب تعلم اللغة الثانية وشرط من

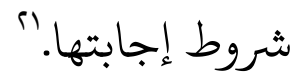
والسؤال الآن: ما معنى أن دارسا أجنبيا قد تعلم كلمة عربية؟ قد برى البعض أن تعلم الدارس الأجنبي معنى كلمة عربية بعني قدرته على ترجمتها ألى لغته القومية وإيحباد مقابل لها. لها.

${ }^{18} \mathrm{Abdul}$ Majid. Perencanaan Pembelajaran (Bandung: Remaja Rosdakarya, 2008), Hal. 174.

${ }^{19}$ Abdul Hamid dkk., Pembelajaran Bahasa Arab ; Pendekatan, Metode, Strategi, Materi dan Media (Malang: UIN Malang Press, 2008), Hal. 71.

"رشدي أممد طعيمة، المرجع في تعليم اللغة العربية للناطقين بلغات أخرى، القسم الأول (مكة: جامعة أم القرى،

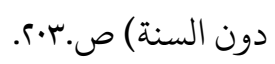

"رشدي أحمد طعيمة، تعليم العربية لغير الناطقين بها مناهجه واساليبه.(مصر: البرباط.|2|ه-9191م) ص ع9.1. 
والبعض الآخر قد يظن أن تعلم الكلمة العربية يعني قدرته على تحديد معناها في القواميس

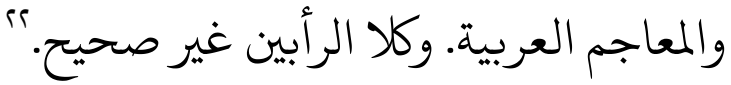
ليست القضية في تعليم المفردات أن يتعلم الطالب نطق حروفها فحسب، أو أو فهم

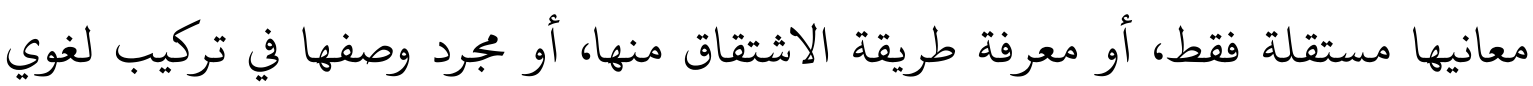

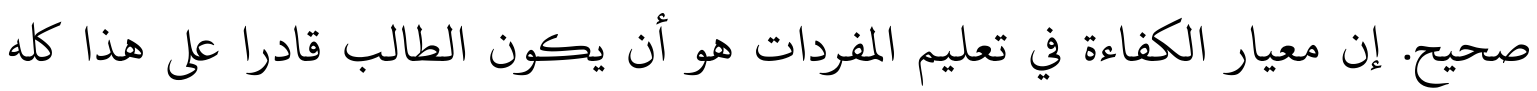

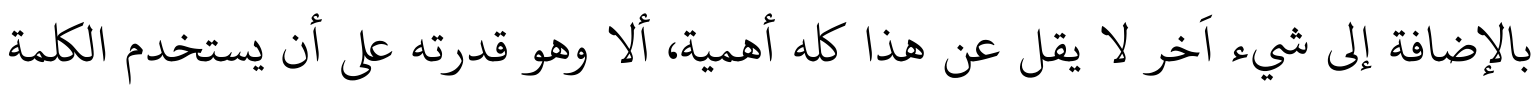

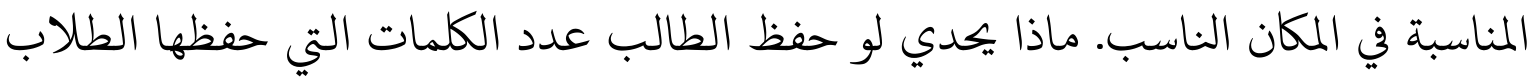
يعتبر عملا غير علمي بل ومضيعا للوقت والجهد، ولاطائل تحته. إن المعيار الحقيقي لتقويم هذا البرنامج يكمن في عدد المواقف التي يستطيع الطالب الاتصال منها بالعربية، وعدد ولئي

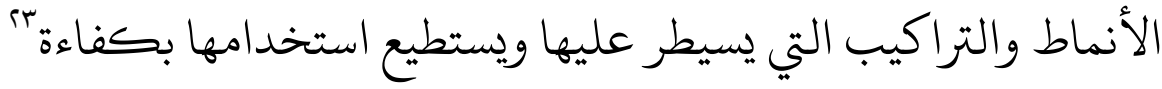

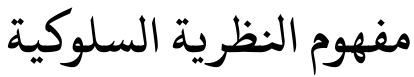

السلوك لغة السير والتصرف، ؛ُ، والسلوك اصطلاحا التصريفات التي تصدر عن الكائنات الحية بما فيها الإنسان، تلك التي يمكن التحكم فيها ثم ملاحظتها واختبارها بموضوعية. فالنظرية السلوكية هي النظرية التي تهتم بدراسات العلاقات بين الحوادث البيئية (المثيرات) وأفعال الكائن الجي(الاستجابات)، وذلك بالبحث عن كيفية إحداث المثيرات

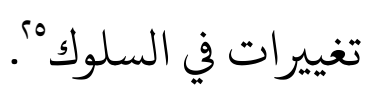

ذهب هذه النظرية أن السلوك البشري هو السلوك الذي يمكن تعلمه وملاحظته

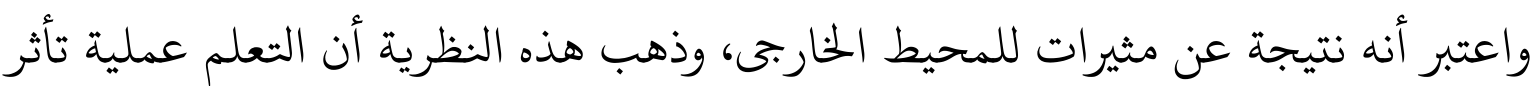

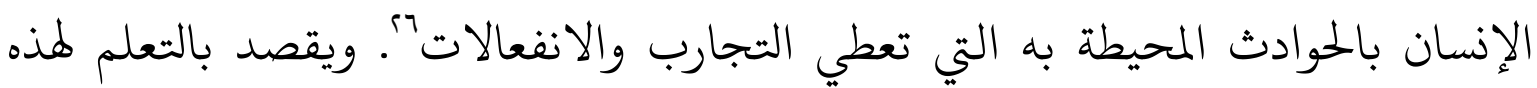

$$
\begin{aligned}
& \text { "رشدي أحمد طعيمة، تعليم العربية لغير الناطقين بها مناهجه واساليبه. ص ع19. }
\end{aligned}
$$

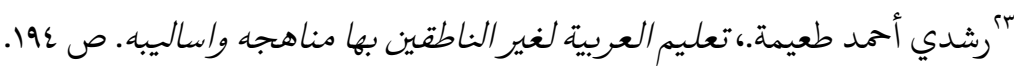

${ }^{24} \mathrm{Ahmad}$ Warson Munawir, Al-Munawwir; Kamus Arab-Indonesia (Yogyakarta: Pustaka Progresif, 2007), Hal. 653.

منعبد العزيز بن إبراهيم العصيلى، النظريات اللغوية والنغسية وتعليم اللغة العربية (جامعة الإمام محمد بن سعود

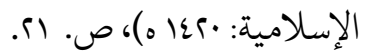

26Djaali, Psikologi Pendidikan (Jakarta : Bumi Aksara, 2011), Hal. 78. 


$$
\begin{aligned}
& \text { النظرية هو تغيير السلوك الذي يحدث بسبب وجود المثيرات والاستجابات ومن المثيرات هي }
\end{aligned}
$$

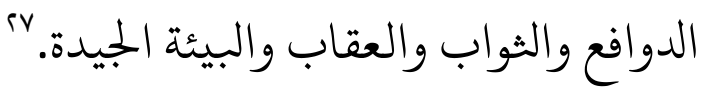

\section{مفهوم تعليم المفردات على أساس النظرية السلوكية}

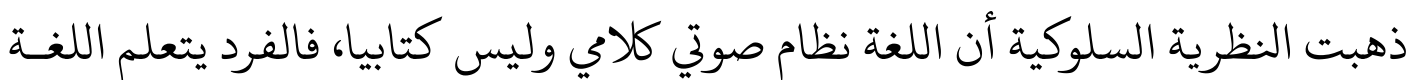

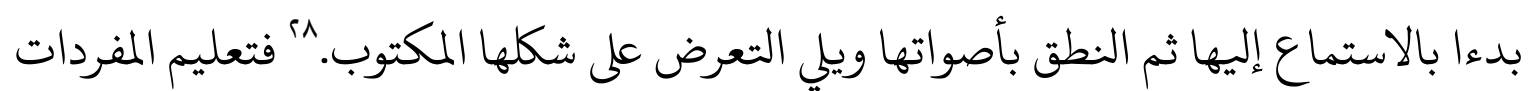
على أساس هذه النظرية يبدأ من الاستماع ثم الكلام ثم الكتابة.

وإن هدف تعليم اللغة عند النظرية السلوكية هو الكلام في تلك اللغة ولـيس الـكلام عن تلك اللغة أي استخدام اللغة للاتصال، وْهدف تعليم المفردات على أساس هذه النظرية

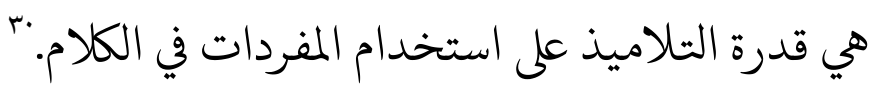

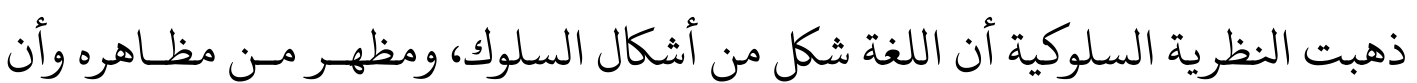

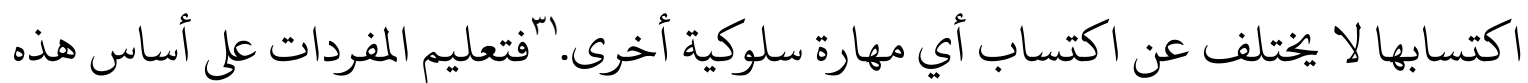

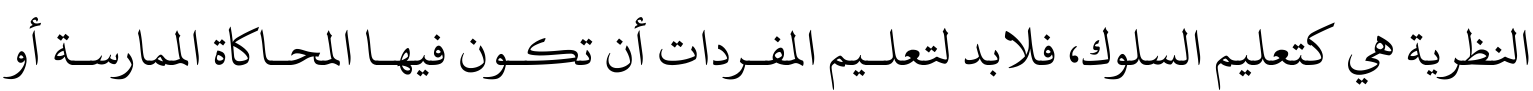
التدريبات المستمرة.

وذهبت النظرية السلوكية أن البيئـة التعليميـة وسـيلة لتشـكيل اسـتجابة المـتعلم

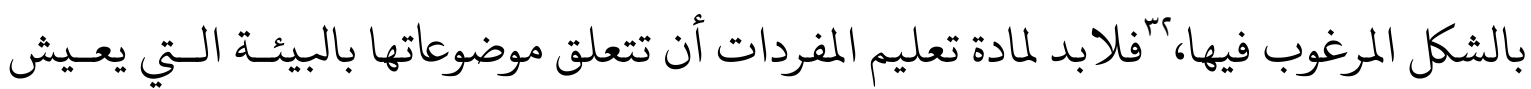
فيها الطلبة.

وتكون معيار كفاءة تعليم المفردات على أساس هذه النظرية كما يلي:

$$
\begin{aligned}
& \text { 1 - قدرة الطلبة على استماع نطق المفردات استماعا صحيحا } \\
& \text { Y - قدرة الطلبة على نطق المفردات نطقا سليما } \\
& \text { "- قدرة الطلبة على فهم معاني المفردات فهما سليما }
\end{aligned}
$$

${ }^{27}$ Aziz Fakhrurrozi dan Erta Mahyudin, Pembelajaran Bahasa Arab (Jakarta: Direktor Jendral Kementrian Agama, 2012), Hal. 45.

${ }^{28}$ Aziz Fakhrurrozi dan Erta Mahyudin, Pembelajaran Bahasa Arab, Hal. 46.

${ }^{29}$ Aziz Fakhrurrozi dan Erta Mahyudin, Pembelajaran Bahasa Arab, Hal. 11.

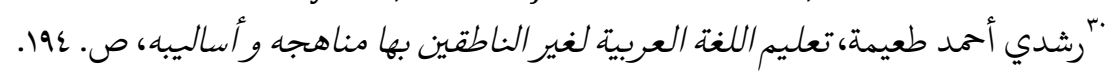

${ }^{31}$ Aziz Fakhrurrozi dan Erta Mahyudin, Pembelajaran Bahasa Arab, Hal. 24.

${ }^{32}$ Aziz Fakhrurrozi dan Erta Mahyudin, Pembelajaran Bahasa Arab, Hal. 11. 
TSAQOFIYA : Jurnal Pendidikan Bahasa dan Sastra, 2 (1), 2020

$$
\text { ـ ـ - قدرة الطلبة على قراءة المفردات قراءة سليمة }
$$

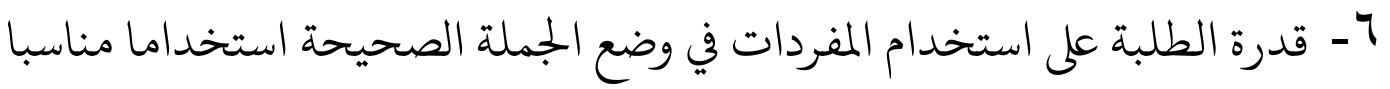

$$
\text { V- قدرة الطلبة على استخدام المفردات في الحوار استخداما مناسبا }
$$

وأما الأساليب في تعليم المفردات على أساس النظرية السلوكية هي كما يلي:

ا - استماع المفردات، هذه مرحلة إعطاء الفرصة للتلاميذ لاستماع المفردات من المعلم. r - نطق المفردات، هذه مرحلة إعطاء الفرصة للتلاميذ لنطق المفردات التّى قد سمعوها.

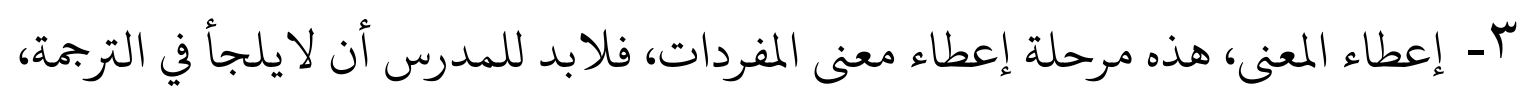

$$
\text { ويمكن استخدام الأساليب الآتية: إعطاء المعنى هذه مرحلة إعنى }
$$

أ. إبراز ما تدل عليه الكلمة من أشياء كأن تعرض قلما أو كتابا عندما ترد كلمة قلم

$$
\text { أو كتاب. }
$$

ب. تمثيل المعنى كأن يقوم المعلم بفتح الباب عندما ترد جملة فتح النافذة

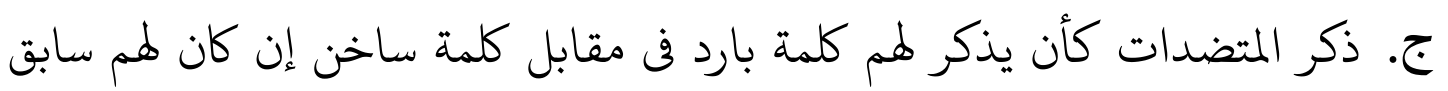

عهد بها.

د. ذكر المترادفات كأن يذكر لهم كلمة السيف لتوضيح معنى كلمة صمصام إن كان لهم سابق عهد بكلمة سيف

ه. لعب الدور كأن يلعب المعلم دور مريض يحس بألم في بطنه ويفحصه طبيب.

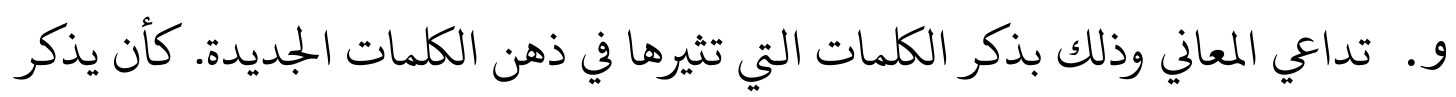
عند ورود كلمة "عائلة" الكلمات الاتية : زوج وزوجة وأسرة وأولاد...إلخ.

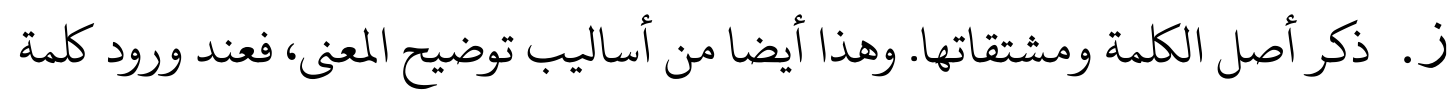

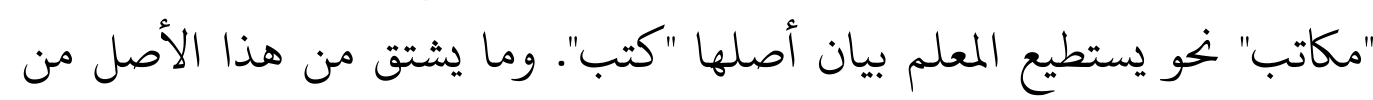

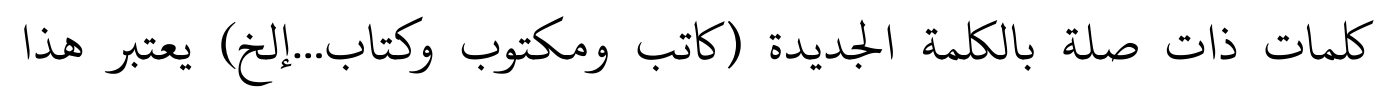
الأسلوب أكثر فاعلية في اللغات التي تعتمد على الإلصاق أي تشيع فيها ظاهرة إلحاق الزوائد على الكلمات المتغيرة من معناها نخو الإنجليزية. ح. شرح معنى الكلمة العربية وذلك بشرح المقصود من الكلمة 
ط. تعدد القراءة، في حالة ورود الكلمة الجديدة في نص يقرؤه الطلاب يمكن

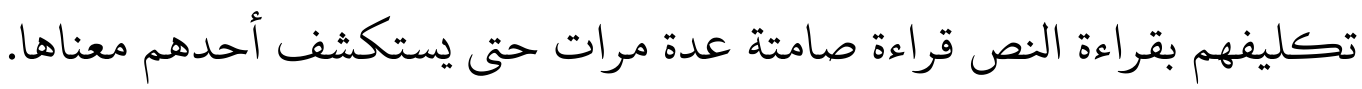

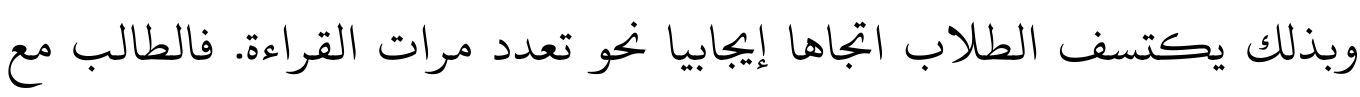

$$
\text { تعدد مرات القراءة يفهم أكثر البكر }
$$

ي. البحث في القاموس، يمكن تكليف الطلاب في المستويات المتوسطة والمتقدمة بالبحث في القواميس العربية لتوضيح معنى الكمة الجمب الجديدة.

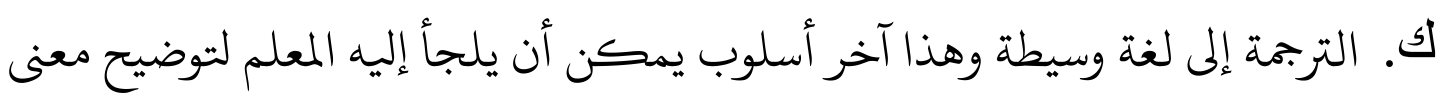
الكلمة وعلى المعلم ألا يتعجل في هذا الأمر.

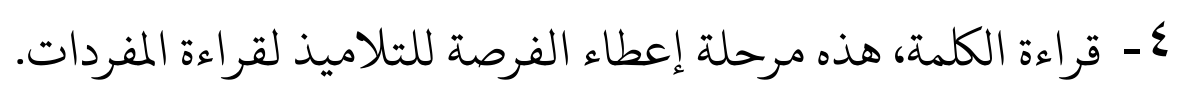
0ـ كتابة المفردات، هذه مرحلة إعطاء الفرصة للتلاميذ لكتابة المفردات.

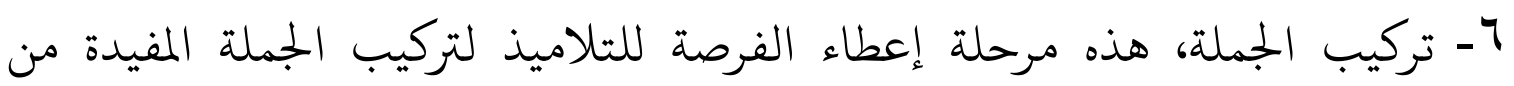

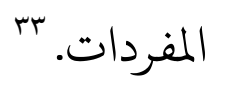

V- تطبيق الكلمة في الحوار، هذه مرحلة إعطاء الفرصة للتلاميذ لاستخدام المفردات في الحوار.

تطوير مادة تعليم المفردات لبرنامج “صباح اللغة” على أساس النظرية السلوكية لطلبة معهد

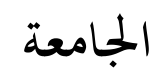

قام الباحث بعملية البحث والتطوير الذي صممه Borg و Gall على شكل شرح

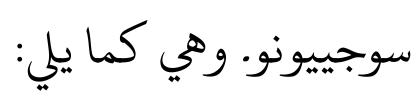

ا. قام الباحث بتحديد المشكلات فقام الباحث بملاحظة عملية تعليم المفردات في

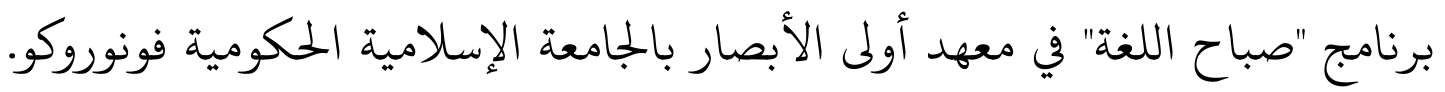

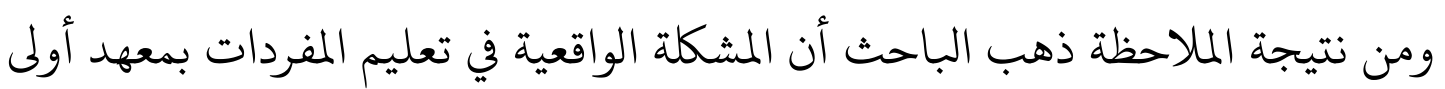

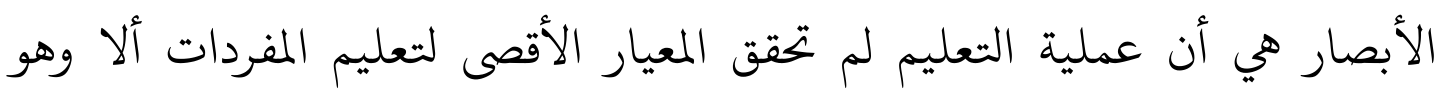

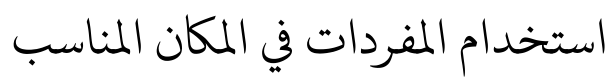

${ }^{33}$ Ahmad Fuad Effendi, Metodologi Pembelajaran Bahasa Arab, Hal. 99. 


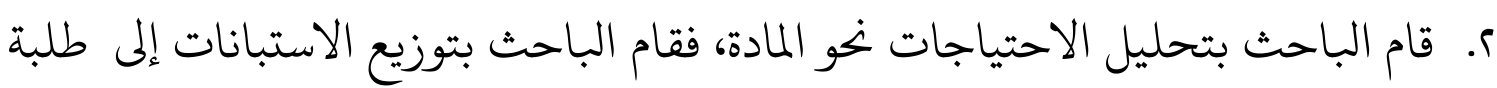
معهد أولي الأبصار ونتيجة تحليل بيانات الاستبانة أن الطلبة في حاجة ماستة كتاب تعليم المفردات r. قام الباحث بجمع المعلومات المستخدمة لتطوير مادة تعليم المفردات بوسيلة الملاحظة والمقابلة والواثقية

ع. قام الباحث بتصميم إطار تعليم المفردات على أساس النظرية السلوكية وتصميم هيكل

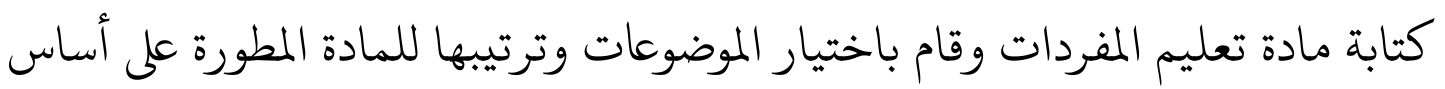

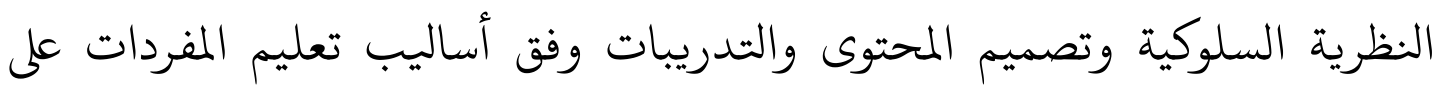

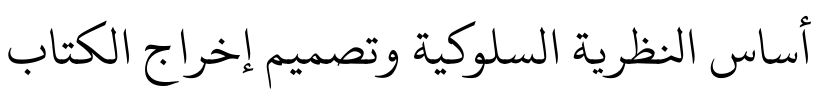
ه. قام الخبير في مجال تعليم اللغة العربية والخبير في مجال تصميم المادة التعليمية بتصديق

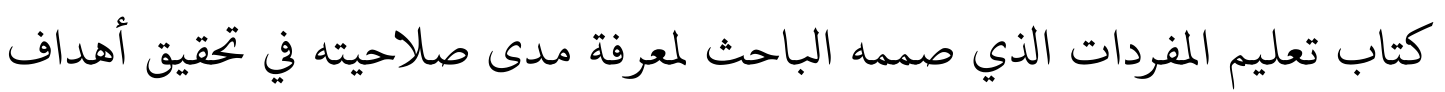
تعليم المفردات في معهد الجامعة الإسلامية الحكومية فونوروكو.

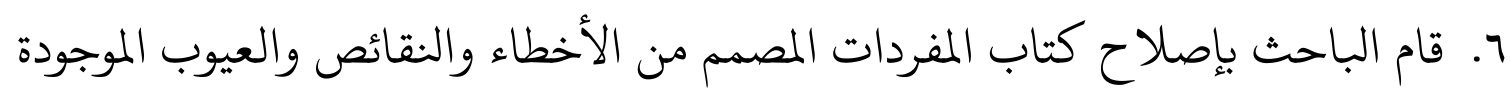

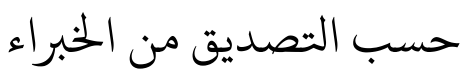
V. قام الباحث بتجربة كتاب المفردات المطور لمعرفة مدى فعاليته في تحقيق أهداف تعليم المفردات في معهد الجامعة الإسلامية الحكومية فونوروكو.

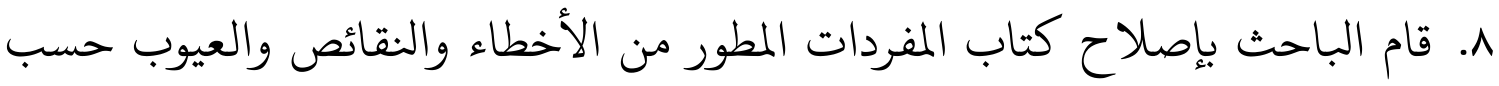
التحليل والثقويم من نتيجة التجربة. 9. قام الباحث بتجربة استخدام المادة المطورة في تعليم المفردات لمعرفة تعليقات الطلبة عنها. •. قام الباحث بإصلاح كتاب المفردات المطور من الأخطاء والنقائص والعيوب حسب

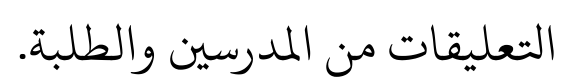

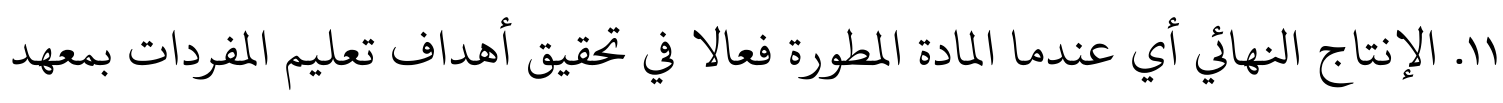

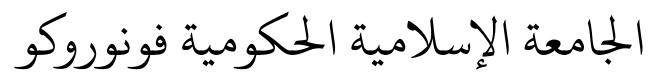




\section{صلاحية مادة تعليم المفردات على أساس النظرية السلوكية لطلبة معهد الجامعة}

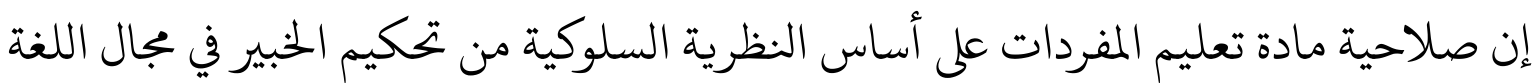

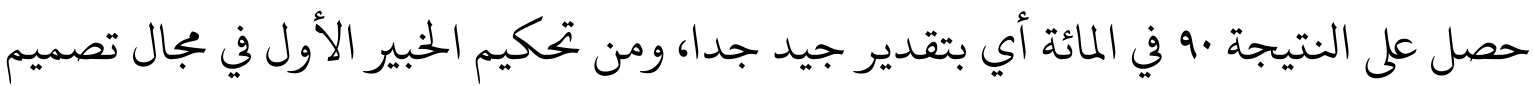

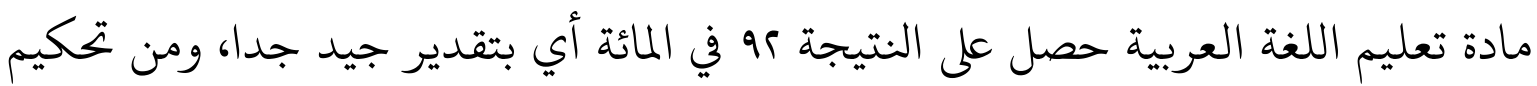

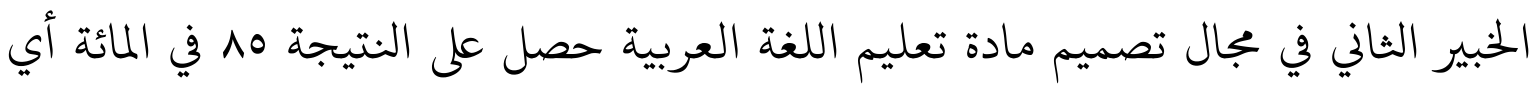

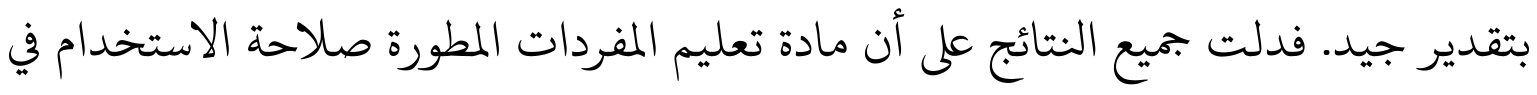

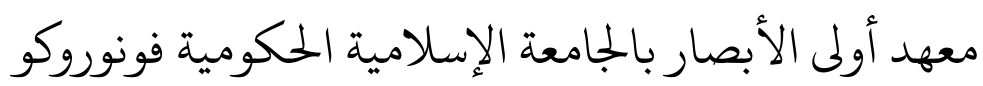

\section{فعالية مادة تعليم المفردات على أساس النظرية السلوكية لطلبة معهد الجامعة}

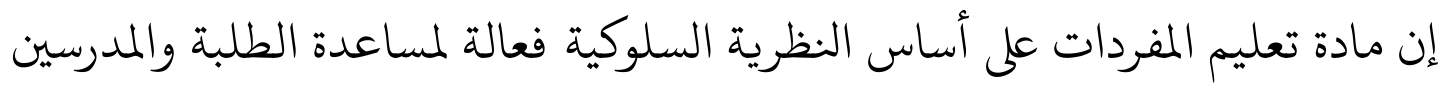

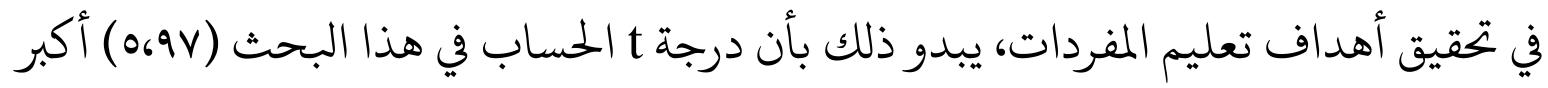

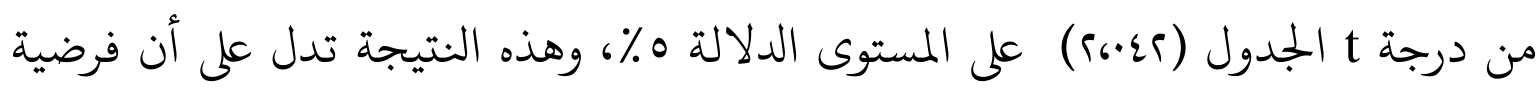

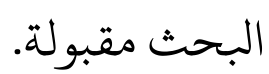

\section{مواصفات مادة تعليم المفردات على أساس النظرية السلوكية لطلبة معهد الجامعة}

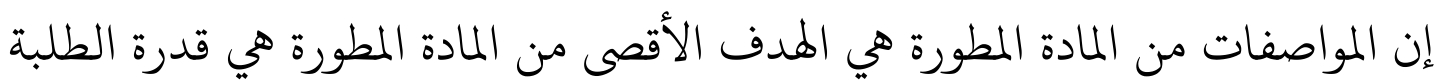

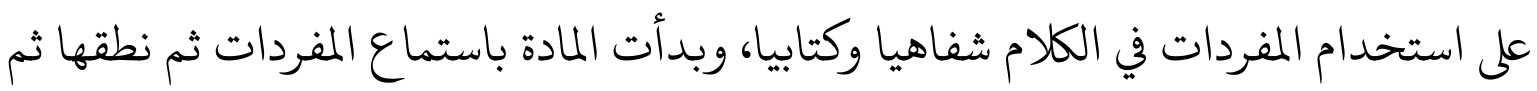
قراءتها ثم كتابتها ثم وضعها في الجملة ثم استخدامها في الحوار، وهذه المادة محاكات وممارسات

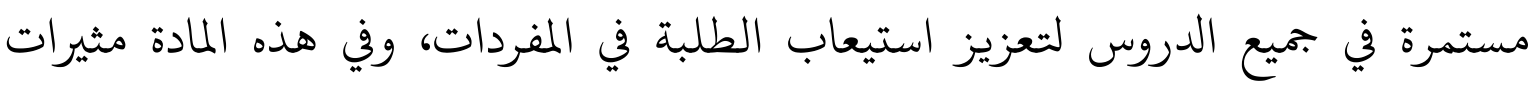

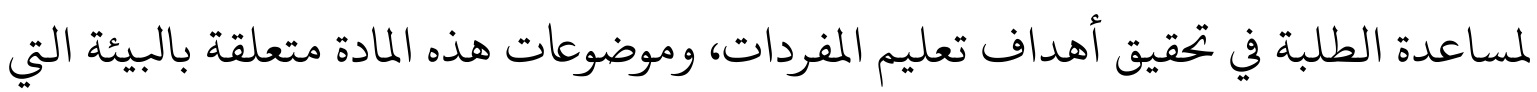
يعيش فيها الطلبة، والمفردات مختارة على أساس التواتر، ومادة تعليم المفردات يتكون من المنات ثلاثة أقسام، هي المفردات الإسمية والمفردات الفعلية والحوار. 
قام الباحث بعملية البحث والتطوير الذي صممه Borg و Gall على شكل شرح

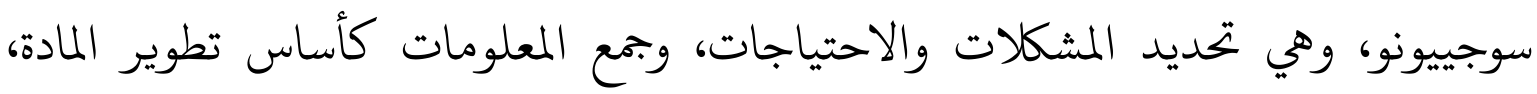

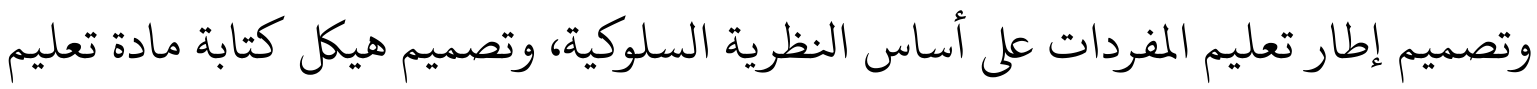
المفردات، واختيار الموضوعات وترتيبها، وتصميم المحتوى والتدريبات، وتصميم إخراج

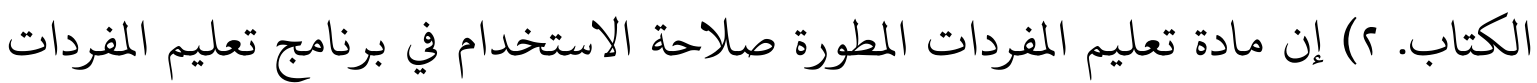

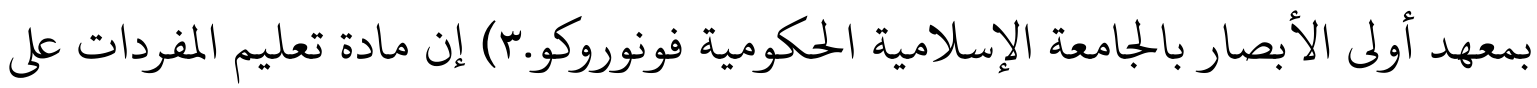

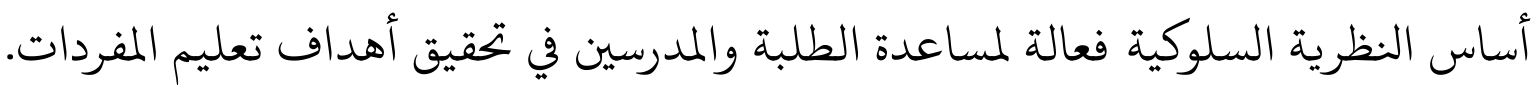

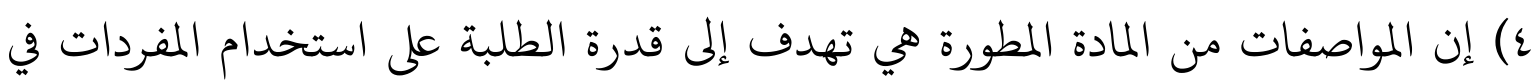

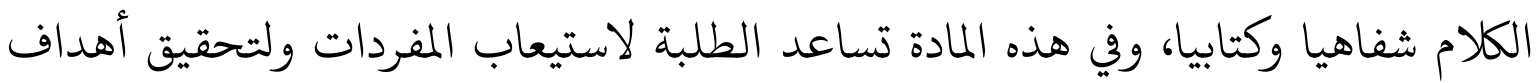

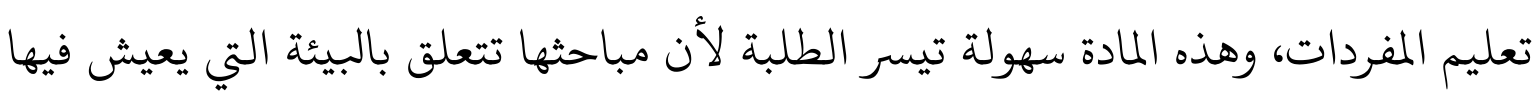

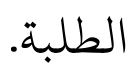

\section{قائمة المصادر والمراجع}

$$
\text { أ- الباري. المراجع العربية المعليم المفردات اللغوية. عمان: دار المسيرة. }
$$

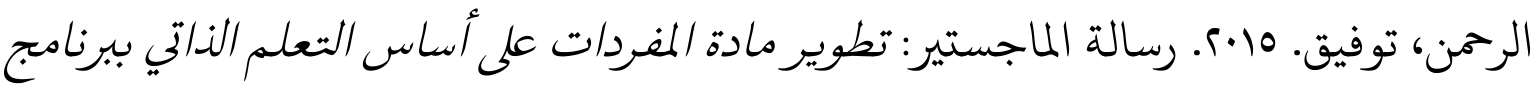

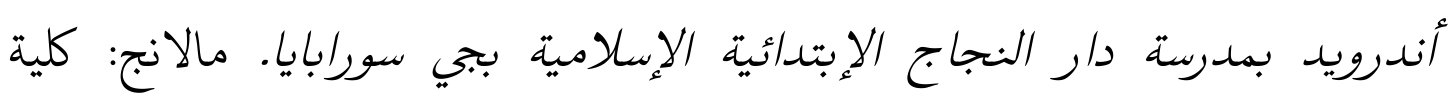

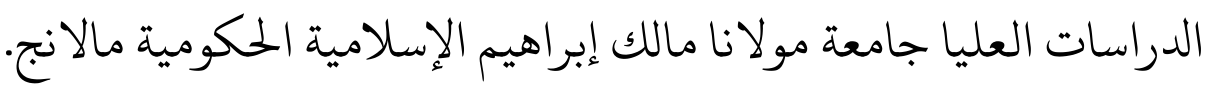

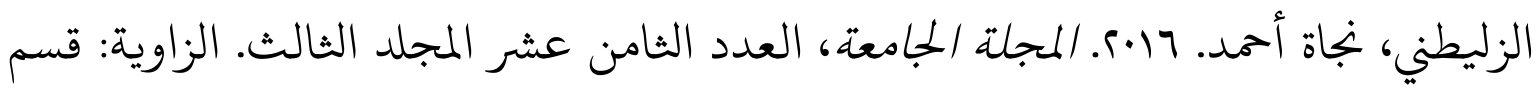
التربية وعلم النفس. العربي، صلاح عبد المجيد. ال191. تعلم اللغات الحية وتعليمها ـ بيروت: مكتبة لبنان. العصيلى، عبد العزيز بن إبراهيم. ..... النظريات اللغوية والنفسية وتعليم اللغة العربية. جامعة الإمام محمد بن سعود الإنلامية. 
الغالي، ناصر عبد الله وآخرون، دون السنة. أسس إعداد الكتب التعليمية لغير الناطقين

$$
\text { بالعربية. الرياض: دار الإعتصام. }
$$

الناقة، محمود كامل ورشدى أحمد طعيمة، بم19. الكتاب الأساسي لتعليم اللغة العربية للناطقين بلغات أخرى إعداده - تحليله - تقويمه. مكة المكرمة: جامعة أم القرى

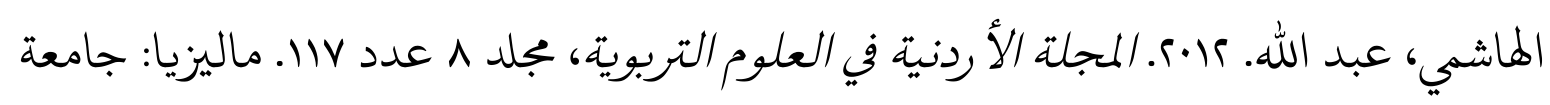
العلوم الإسلامية.

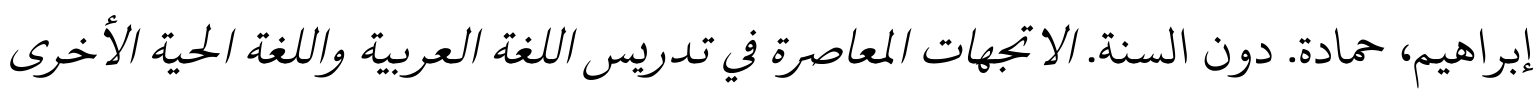

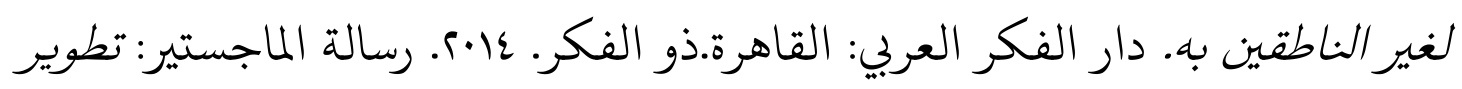

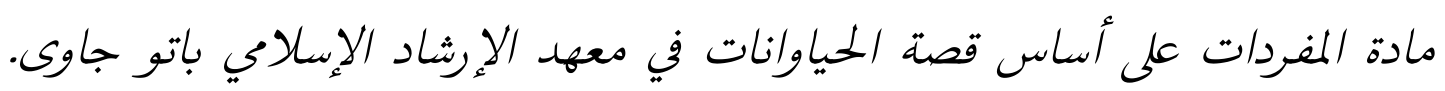
مالانج: كلية الدراسات العليا جامعة مولانا مالك إبراهيم الإسلامية الحكومية مالانج. زين الدين، نور حميمي بن. كا.؟. تحليل الاحتياجات في تطوير الوسائط المتعددة في تعليم مفردات اللغة العربية وتعلمها عبر برنامج موودل. ماليزيا: الجامعة الإسلامية العالمية ماليزيا.

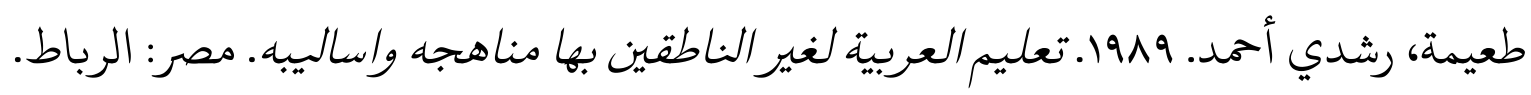

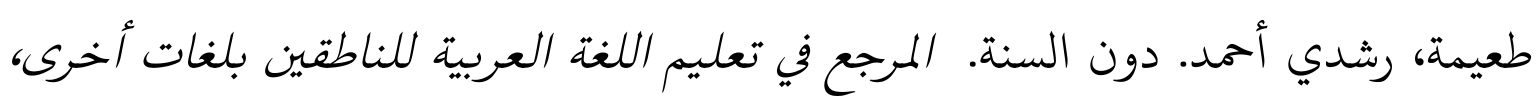
القسم الأول. مكة: جامعة أم القرى.

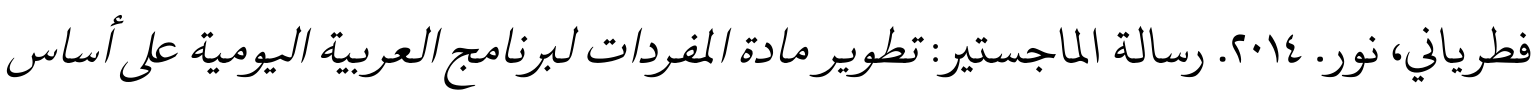

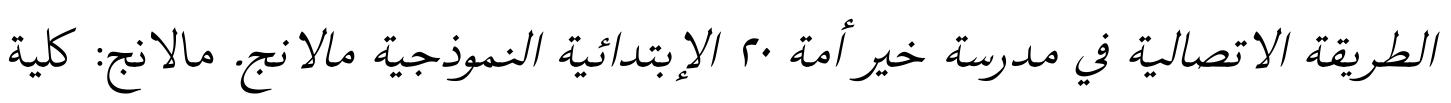
الدراسات العليا جامعة مولانا مالك إبراهيم الإسلامية الحكومية مالانج.

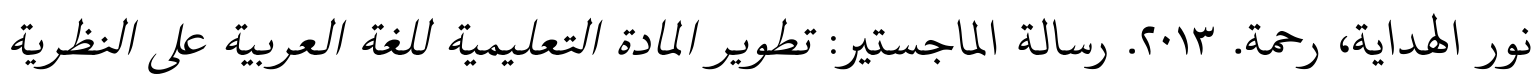
السلوكية في مدرسة بني هاشم المتوسطة الإسلامية مالانج. مالانج: كلية الدراسات العليا جامعة مولانا مالك إبراهيم الإسلامية الحكومية مالانج.

Abdurochman. 2017. An-Nâbighoh, Volume IXX No. 1.

Djaali, 2011. Psikologi Pendidikan. Jakarta : Bumi Aksara. 
Effendi, Ahmad Fuad 2004. Metodologi Pembelajaran Bahasa Arab. Malang:Misykat.

Fakhrurrozi dan Erta Mahyudin, Aziz. 2012. Pembelajaran Bahasa Arab. Jakarta: Direktor Jendral Kementrian Agama

Faryadi. Qais. 2007. Behaviorism and the Construction of Knowledge (University: UiTM Malaysia.

Hamid dkk, Abdul. 2008. Pembelajaran Bahasa Arab: Pendekatan, Metode, Strategi, Materi dan Media. Malang: UIN Malang Press.

Irwan. 2015. Jurnal PPKn \& Hukum, Vol. 10 No. 2. Sumatera Barat: Institut Seni Indonesia.

Majid. Abdul 2008. Perencanaan Pembelajaran. Bandung : Remaja Rosdakarya.

Mofareh Al-Qahtani. 2015. International Journal of Teaching and Education, Vol. III No. 3. Saudi Arabia: King Khaled Academy.

Mothe. Prashant Subhash, Innovative Techniques of Teaching Vocabulary at the Intermediate Level in the Second Language Classroom. India: Adarsh Senior College.

Munawir, Ahmad Warson. 2007. Al-Munawwir: Kamus Arab-Indonesia. Yogyakarta: Pustaka Progresif.

Mustofa, Syaiful. 2011. Strategi Pembelajaran Bahasa Arab Inovatif. Malang : UIN Malang Press.

Nahar, Novi Irwan. 2016. Nusantara ( Jurnal Ilmu Pengetahuan Sosial ), Vol. 1. Sumatera Barat.

Sugiono, 2010. Metode Penelitian Kuantitatif, Kualitatif, dan R\&D. Bandung: Alfabeta.

Wajdi, Muh. Barid Nizaruddin. 2016. Jurnal Ilmu Tarbiyah “At-Tajdid”, Vol. V No. 1. Nganjuk: STAI Miftahul Ula.

Zheng, Shigao. 2012. English Language Teaching, Vol. 5, No. 5. www.ccsenet.org. 